\title{
Antik Yazarların Eserlerinde Adiabene Bölgesi ile İlgili Anlatımlar
}

\author{
Ercüment YILDIRIM \\ Kahramanmaraş Sütçü İmam Üniversitesi \\ neshali@gmail.com \\ ORCID ID: 0000-0001-5376-4061
}

\begin{tabular}{lrr} 
Araştırma Makalesi & DOI: $10.31592 /$ aeusbed.907111 \\
\hline Geliş Tarihi: 31.03 .2021 & Revize Tarihi: 06.07.2021 & Kabul Tarihi: 19.07.2021
\end{tabular}

\section{Atıf Bilgisi}

Yıldırım, E. (2021). Antik yazarların eserlerinde Adiabene bölgesi ile ilgili anlatımlar. Ahi Evran Üniversitesi Sosyal Bilimler Enstitüsü Dergisi, 7(2), 485-497.

\section{ÖZ}

Seleukos Krallığı'nın güç kaybetmesinden sonra binyıllarca Asur Krallığı'nın merkezi olan coğrafyada ortaya çıkan Adiabene, bağımsızlığını sürdürdüğü yaklaşık yüzyıl boyunca Romalılar ve Partlar arasında tampon bir krallık olarak kalmıştır. Adiabene Krallığı'nın kurulmuş olduğu bölge, batıda Dicle Nehri, güneyde Küçük Zap Nehri, kuzeyde antik yazarların tanımı ile Gordyaean Dağları doğuda ise Zağros Dağları'nın batı yamaçları ile çevrilidir. Adiabene Krallığı ile ilgili anlatımlarda bulunan antik yazarların büyük çoğunluğu bu coğrafyada Ninova şehrinin ve Gaugamela'nın bulunduğunu belirtmektedir. Yine Antik kaynaklara göre Adiabene'nin bilinen ilk kralı Artaxares iken en güçlü döneminin II. Izates zamanında yaşandığ 1 bilinmektedir. Josephus'a göre II. Izates döneminde Adiabene Krallı̆̆ı, Yahudi dinini kabul etmiştir. Fakat bu dini değişikliğin kraliyet ailesi ile sınırlı kalmış olduğu düşünülmektedir. Adiabene bölgesi ile ilgili antik yazarlardan Strabon, Ammianus Marcellinus, Plutarkhos, Josephus, Tacitus ve Cassius Dio anlatımlarda bulunmaktadır. $\mathrm{Bu}$ anlatımlar, çoğunlukla krallığın konumu ve Roma - Part mücadelesine odaklanmıştır. Yine antik yazarlardan edinilen bilgiye göre Roma İmparatoru Traianus, MS 113 yılında Part Krallığı üzerine çıktığı seferde Adiabene Krallığını, Roma yönetimi altına almıştır. Sonrasında Adiabene Krallığının toprakları, Roma'nın Assyria eyaletine dönüştürülmüştür. Bu tarihten sonra Adiabene Krallığ1 gücünü tekrar toplayamamış ve bağımsız bir yönetime sahip olamamıştır. Bu çalışma Adiabene Krallığına dair antik kaynaklarda yer alan anlatımları bir araya getirerek krallığın tarihi hakkında genel bilgi vermeyi amaçlamaktadır.

Anahtar Kelimeler: Adiabene, Seleukos, Asur, II. Izates, Ninova.

\section{Adiabene Region Related Expressions on the Works of Ancient Authors}

\begin{abstract}
Adiabene, which emerged in the geography that was the center of the Assyrian Kingdom for millennia after the loss of power of the Seleucid Kingdom, remained a buffer kingdom between the Romans and the Parthians for about a century when it remained independent. The region where the Kingdom of Adiabene was established is surrounded by the Tigris River in the west, the Küçük Zap River in the south, the Gordyaean Mountains as the ancient authors describe it in the north and the western slopes of the Zagros Mountains in the east. Most of the ancient writers who have narrated about the Kingdom of Adiabene state that there is the city of Nineveh and Gaugamela in this geography. According to ancient sources, it is known that the first known king of Adiabene was Artaxares, while the most powerful period was experienced during the period of Izates the second. According to Josephus, during the period of Izates the second, the Kingdom of Adiabene adopted the Jewish religion. However, this religious change is thought to have been limited to the royal family. Ancient writers such as Strabon, Ammianus Marcellinus, Plutarch, Josephus, Tacitusve Cassius Dio, have narrations about Adiabene region. These accounts mostly focused on the location of the kingdom and the Roman-Parthian struggle. Again, according to the information obtained from ancient writers, the Roman Emperor Trajan took the Adiabene Kingdom under Roman rule when he went to campaign on the Parthian Kingdom in 113 AD. Later, the lands of the Adiabene Kingdom were transformed into the Roman province of Assyria. After this date, the Kingdom of Adiabene could not regain its power and have an independent administration. This study aims to give general information about the history of the kingdom by bringing together the accounts of the ancient sources about the Kingdom of Adiabene.
\end{abstract}

Keywords: Adiabene, Seleucid, Assyria, Izates II, Nineveh.

\section{Giriş}

Antik kaynaklarda Adiabene olarak isimlendirilen bölge, Asur krallığının merkezi coğrafyasını oluşturmaktadır. Bölge, MÖ (Milattan Önce) 2000'li yıllardan MÖ 612 yılına kadar geçen sürecin büyük kısmında Asur yönetimi altında kalmıştır. $\mathrm{Bu}$ dönemde nüfusun büyük çoğunluğunu Asurlular oluşturmasına rağmen Hurri toplumunun da bölgenin etnik yapısında önemli 
bir yeri olduğu bilinmektedir. Hurri toplumunun Mitanni halk1 ile birlikte devletleşme aşamasına ulaştığı yaklaşık MÖ 1450 - 1350 yıllarında Adiabene Krallığı'nın sahip olacağı toprakları yönetmiş̧ir. Bir taraftan Hititlerin düzenlediği askeri seferler diğer yandan Asur'un genişlemesi sonucunda yıkılan Hurri-Mitanni Krallığı Asur'un yönetimi altına girmiştir. Deniz Kavimleri Göçleri'nden sonra etnik ve siyasal açıdan dönüşüme uğrayan Ön Asya'nın en güçlü devleti haline gelen Asur, sınırlarını günümüz Doğu Anadolu'sundan Orta İran'a kadar genişletirken; Doğu Akdeniz kıyıları ile Mısır'ı da yönetimi altına almayı başarmıştır. Bu geniş coğrafyanın merkezinde ise Adiabene Krallığı'nın bulunacağı coğrafya kalmıştır (Gökçek, 2015, ss. 35 - 109; Kralsson, 2016; Larsen, 1977, ss. 119 - 145; Yamada, 2000).

Asur tarihinin son dört yüz yıllık safhasını oluşturan Yeni Asur Krallığı döneminde askeri, siyasi ve ekonomik büyük gelişmeler yaşanmıştır. Birbiri ardına gelen güçlü Asur kralları, düzenledikleri askeri seferler ile Ön Asya dünyasının tamamından vergi alır hale gelmiştir. Alınan bu vergiler ile zenginleşen Asur kralları, Adiabene'nin yer alacağı bölgede birçok gösterişli kent inşa ettirmişlerdir. Bunlar içerisinde en ünlüsü ise Ninova şehri olmuştur. Ninova şehrinin önemi döneminin en eşsiz mimari yapısını yansıtmasının ötesinde Asurbanipal tarafından kurulan kütüphane ile bir medeniyet merkezi olmasından gelmektedir (Ataç, 2010, ss. 167 - 171; Holloway, 2002, ss. 320 - 338; Liverani, 2017, ss. 534 - 545; Parpola, 2004, ss. 5 - 49).

\begin{abstract}
“Nabopolassar'ın kralliğının on dördüncü (MÖ 612) yllinda Akad (Babil) kralı ordusunu topladı ve Asur'a yürüdü, Med kralı da Akad (Babil) kralına doğru yürüdü, (sonra) birbirleri ile buluştular. Akad (Babil) kralı ve Med kralı birlikte Dicle Nehri boyunca ilerleyerek Ninova şehrinin karşısında kamp kurdular. Simanu ayından (Mayls - Haziran) Abu ayına (Temmuz Ăgustos) kadar ü̧̈ ay boyunca şehre (Ninova'ya) ăgır saldırllar düzenlediler. Abu ayının bir gününde onlar yenilgiye uğradı (şehir düştü). (Ordular) tapınağın ve sarayın büyük ganimetlerini yağmaladl ve şehri bir harabe haline getirdiler." (Kuhrt, 2010, s. 31).
\end{abstract}

Ninova şehrinin Medlerin eline geçmesi ve yıkılışını anlatan çivi yazılı metinde görüldügü üzere Adiabene bölgesinin en ihtişamlı ve merkezi kentinin yıkılması ile binyıllar süren Asur medeniyeti ve zenginliği ortadan kalkmıştır. Bölge, Medlerin yönetimi altına girmiş ve bir daha siyasi merkez olma vasfını kazanamamıştır. Bunun ötesinde Medler ve akabinde Persler, Ninova kenti başta olmak üzere bölgeye farklı coğrafyalardan insan gruplarını yerleştirmişlerdir. Bu durumun temelinde bölgede kalan Asur toplumunun merkezi yönetime isyanını engellemek bulunmaktadır. Medler tarafından yıkma uğratılan Ninova ve bölgenin diğer kentleri Asur döneminde kazandıkları ticari merkez olma vasfinı da kaybetmiştir. Perslerin Mezopotamya'nın tamamını hakimiyetine almasından sonra bölge, Babil Satraplığına bağlamış ve ağır vergiler altında ezilmiştir (Jhonston 1901, ss. 20 - 22; MacGinnis, 1988, ss. 37 - 42; Zawadzki, Wolko, Lavelle, 1988).

Adiabene bölgesinde yaklaşık üç yüz yıl süren Pers hakimiyetinin ardından Makedon hakimiyeti başlamıştır. Doğu seferine çıkan ve Pers topraklarının çoğunluğunu ele geçiren Büyük İskender, Mısır'dan dönüş yolunda Persler ile son savaşını Adiabene bölgesi sınırları içerisinde bulunan Gaugamela'da yapmıştır. Gaugamela'nın günümüzde Musul'un hemen doğusunda yer aldığ1 kabul edildiğinde MÖ 322 tarihinde Adiabene bölgesinin Perslerden Makedon yönetimine geçtiği görülmektedir. Büyük İskender sonrası oluşan yönetimde Seleukos Krallığı hakimiyetinde kalan Adiabene bölgesi, Seleukosların yönetimlerinin zayıflaması ile bağımsız bir krallık haline gelmiştir (Cline ve Graham, 2011, ss. 485 - 486; Marciak, 2014a, ss. 111 - 124; Reade, 1998, ss. 65 - 83).

Bu çalışma, MS (Milattan Sonra) 1. yüzyılda bağımsız bir krallık olan Adiabene'ye dair antik kaynaklarda yer alan anlatımları bir araya getirerek krallığın tarihi hakkında genel bilgi vermeyi amaçlamaktadır. Bu amaç gerçekleştirilirken, Adiabene Krallığı'nın kurulmasından öncesindeki siyasi gelişmeler hakkında bilgi verilerek dönemin olayları daha anlaşılır kılınmaya çalışılmıştır. Antik yazarlardan Strabon, Ammianus Marcellinus, Plutarkhos, Josephus, Tacitus ve Cassius Dio'dan alıntılar yapılmış ve bu alıntılar, diğer tarihsel kayıtlarla da kıyaslanarak özgün yorumlar üretilmeye gayret gösterilmiştir. 


\title{
Adiabene'nin Coğrafi Sınırları
}

Adiabene Krallığı'nın sahip olduğu toprakların Asur Krallığı'nın merkezi coğrafyası olduğu bilinmesine rağmen antik yazarlar, bölgenin sınırları ile ilgili bilgiler verirken farklı ve benzer görüşler öne sürmüşlerdir. $\mathrm{Bu}$ durumun temelinde siyasi sinırların dönemsel farklılıklar göstermesi, antik yazarların kullandığı farklı coğrafi unsurlar ve bölgenin belirli parçalarının yeni isimlerle anılmaya başlamasının yer aldığı bilinmektedir. Birçok antik yazar Adiabene'yi nehirler ile sınırlamışken bazı yazarlar, komşu olunan diğer krallıkların isimlerini vermiş̧ir. Yine de Adiabene'nin sınırlarını belirten antik yazarlar bölgenin önemli kentlerini de sayarak, şehir lokasyonuna dayalı sınırlandırmada da bulunmuştur.

\begin{abstract}
"Şimdi (benim zamanımda) Ninova şehri, Asur'un yıkılışından hemen sonra tamamen yok edildi. (Ninova şehri) Babil şehrinden daha büyüktü ve Atouria ovasında yer almaktaydl. Atouria Ovast, Erbil bölgesi ile Lykos Nehri arasında uzanmaktadır. (...) Atouria Ovası'nda Darius'un yenildiği ve topraklarını kaybettiği yerde Gaugamela isimli köy de yer alır. Adının anlamı "Deve Evi" olan (Gaugamela) bu yer oldukça ünlüdür. Hystaspes'in oğlu Darius, bu yer (Gaugamela) adını, İskit Çöllerindeki zorlu yolculuklarda kralı destekleyenlere, develerin bakımı için mülk olarak vermesinden sonra almıştır. Ancak bu köyün basit bir yerleşim olduğunu fakat Erbil'in kayda değer bir yerleşim yeri olduğunu gören Makedonlar, (Athmoneos'un oğlu Arbelos tarafindan Erbil'in kurulduğu söylenir) savaşın ve zaferin Erbil yakınlarında geçtiğini söyleyip tarihçilere de böyle aktarmışlardır. Erbil veya Mt. Nikatorion (Erbil yakınlarında kazanılan zaferden sonra İskender buraya bu yeni ismi vermiştir) Lykos Nehri ile Erbil'den aynı uzaklıkta bulunan Kapros Nehri'ne ulaşılır. Bu ülkeye Artakene (Adiabene) ismi verilir. Erbil kentinin yakınında Demetrias şehri bulunur ve (bu şehirde) neft (katran) çeşmesi ve ateşleri, Anea tapınă̆l, Hystaspes 'in oğlu Darius'un kraliyet sarayl, Kapros Nehri'nin geçiş köprüsü olup Seleukos ve Babil'e yakın bir yerdedir." (Strabo, Geographika 16.1.3-4.)
\end{abstract}

MÖ 64 ile MS 24 yılları arasında yaşadığı kabul edilen Strabon, eserinde yaşadığı dönem ve yakın tarih hakkında malumatlar verirken Adiabene bölgesi ile ilgili bilgiler de vermiştir. Strabon'un verdiği bilgiler arasında en önemlisinin Asur'un yıkılışından sonra Ninova kentinin tamamen yok edilişi ve Asur'un bir daha toplanamayıp tarih sahnesinden silinişidir. Sonraki dönemlerde Persler ve akabinde Makedonlar, bölgeyi ve kentlerini kendi lisanları ile yeniden isimlendirmiştir. Örneğin Büyük İskender, Erbil kentine Mt. Nikatorion ismini vermiş fakat bu isim sadece bir dönem kullanılmış ve kent eski ismi ile anılmaya devam etmiştir. Ayrıca Strabon'un da belirttiği gibi Persler ve Makedonlar farklı coğrafyalardan insanları Adiabene'ye yerleştirerek bölgenin etnik yapısının değişmesine de yol açmışlardır. Strabon, Adiabene'nin sınırlarını ise bölgenin büyük nehirlerini referans alarak belirlemiştir. Bu sınırlamadaki nehirlerin Büyük Zab ve Diyala olduğu kabul edilmektedir.

\footnotetext{
"Bu bölgenin içinde eski zamanlarda Asur olarak adlandırllan Adiabene var, ancak bu isim oldukça uzun bir zamanda değiştirildi çünkü Ona ve Dicle Nehirleri arasında uzanan bu yerde

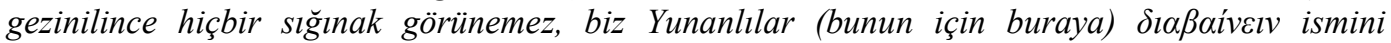
veriyoruz. Bütün bunlar kadim insanların görüşüdür. Fakat ben kendim, bu topraklarda sürekli akan iki nehir olduğunu söylüyorum. Benim de geçtiğim Diabas ve Adiabas üzerinde kaylklardan yapılmış köprüler var (...) Ninova (Ninus) şehri Adiabene olup bu şehir, bir zamanlar Pers ülkesini elinde tutan Semiramis'in kocası güçlü kral Ninus'un adını yaşatmaktadır. Ayrıca Adiabene'de Ecbatana, Erbil ve İskender'in Dairus'u yenmiş olduğu yer olan Gaugamela da bulunmaktadır." (Ammianus Marcellinus, Rerum Gestarum Libri 23.6.20-22)
}

Ammianus Marcellinus, Adiabene bölgesinin sınırlarını belirlemek için bölgede yer alan nehirleri kullanmaktadır. Günümüzdeki gibi kesin sınırları bulunmayan eskiçağ krallıklarında büyük dağlar ve nehirler hem doğal sınır hem de siyasi sınır olarak kullanılabilmekteydi. Fakat Ammianus Marcellinus, bölgenin sınırlarını verirken kendisine daha öncekilerin aktarmış olduğu ile kendisinin gözlemleri ile edindiği bilgiyi ortaya koymaktadır. Yine de sonuçta Dicle Nehri ile Ona (Habur) Nehri arasındaki bölgenin Adiabene olduğunun kabul edilmesi gerektiğini ileri sürmektedir. Ayrıca Ammianus Marcellinus, bölgenin önemli kentlerini sayarken Erbil ve Gaugamela'y1 da bölgeye dahil ederek diğer antik yazarların vermiş olduğu sınırlamayı teyit etmektedir. 


\begin{abstract}
“Asur topraklarının başlangıcı olan Adiabene'nin Suriye'ye yakın olan kısmı, Büyük İskender'in Darius'u yenmiş olduğu (Erbil) Arbelitis'dir. Makedonlar bütün Adiabene’ye Makedon ülkesindeki Mygdonia'ya benzeterek Mygdonia adını vermiştir. Buranın (Adiabene) kentleri Alexandria ve Antioch olup Antioch'un yerli dilindeki adı (Nusaybin) Nisibis'dir. Burası (Nisibis) Artaxata'dan 750 mil uzaklıktadır. (Ayrica Adiabene'de) bir zamanlar Dicle'nin batı kıyısında Ninova isimli bir kent vard ve bu kent çok meşhurdu." (Pliny The Elder, Natural History, 6, 42)
\end{abstract}

Adiabene'nin sınırları ile ilgili bilgi veren bir diğer antik yazar olan Yaşlı Plinius, Adiabene'nin sınırlarının diğer antik yazarlardan daha farklı biçimde aktarmıştır. Yaşlı Plinius, bölgenin nehirleri ile oluşturulan bir sınırlamayı vermek yerine eski Asur topraklarının içerisinde yer alan bölgenin merkezinin Erbil kenti olduğunu belirtmiş ve bölgenin kuzeyde günümüz Nusaybin'e kadar uzanmış olduğunu iddia etmiştir. Ayrıca Yaşı Plinius, diğer antik yazarlardan farklı olarak Makedonların bölgenin tamamının ismini değiştirmiş olduğunu da söylemiştir. Bu farklılığın temel nedenin siyasi sınırların dönemsel farklılıklar göstermesi olduğu kabul edilebilir. Bütün bunların dışında diğer tüm antik yazarlar gibi Yaşlı Plinius'de kadim Ninova kentini anmadan geçmemiş ve Asur'un kraliyet kenti olan Ninova'nın ününden bahsetmiştir.

Antik yazarların anlatımları referans alındığında Adiabene Krallığı'nın batı sınırının Dicle Nehri, güney sınırının Küçük Zap Nehri olduğu kabul edilebilir. Kuzey sınırı, ise Gordyaean Dağları olduğu iddiasından hareketle Van Gölü’nün güneyine kadar genişletilebilir. Adiabene'nin doğu sınırının ise siyasi gücüne nispetle değişmesine rağmen Zağros Dağları'nın batı yamaçlarında son bulduğu tahmin edilmektedir (Marciak, 2011a, ss. 179 - 208; Marciak, 2017, ss. 272 - 291; Reade, 2001, ss. 187 - 199).

\title{
Adiabene Krallığı'nın Kuruluşu
}

Adiabene olarak isimlendirilen bölgenin bağımsız bir yönetime sahip olarak ilk ortaya çıkışı, eldeki verilerin yetersizliği sebebiyle tahminlerin ve kıyaslamaların ötesine geçememektedir. Ön Asya'da Perslerin yükselişi sonrasında Asur'un yıkılışı ile Ön Asya'nın güç merkezi günümüz İ́ran coğrafyasına kayınca Adiabene'nin de içerisinde bulunduğu Kuzey Mezopotamya hakkında yazılı kaynaklar azalmıştır. Büyük İskender'in Pers Krallığını yıkmasından sonra kurulan Helenistik Krallıkların merkezi yönetimleri de Adiabene bölgesine coğrafi olarak uzaktı. Bu durum da Abiabene'nin tarihsel kayıtlarda çok yer tutmamasına neden olmuştur. Adiabene bölgesinin, Kyaksares'in MÖ 612 yılında Ninova kentinin ele geçirilmesi ve Asur'un y1kılışı ile Med yönetimi altına girmiş olduğu kabul edilmektedir. Medlerin bölgeyi ele geçirmesinden sonra Asur Krallığına ait olan tüm kentlerin tahrip edilmiş olduğu ve bölgenin ekonomik olarak çöküşe geçtiği bilinmektedir. Bölgede Med yönetimini devralan Persler, Mezopotamya hakimiyetlerini geliştirmiş ve II. Kyros, Babil'i ele geçirerek, Adiabene bölgesindeki egemenliği daha da güçlendirmiştir (Dalley, 1993, ss. 134 - 147; Mavrojannis, 2017, ss. 121 - 150).

Büyük İskender'in doğu seferine ve Perslerin yıkılışına kadar ihtimalle Babil satraplığına bağlı bir bölge olan Adiabene bölgesi, MÖ 305 yılından sonra Helenistik bir krallık olan Seleukos yönetiminde kalmıştır. Fakat Seleukos I. Nikator, MÖ 300 yılında başkentini Antiokhia'ya (günümüz Antakya'sına) taşıması ile Adiabene, eski kraliyet kenti Babil'e olan yakınlığı ile sağladığı stratejik konumunu büyük ölçüde kaybetmiştir. Bu dönemden sonra Seleukosların, ellerindeki bölgelerin bir kısmını yerel kralların yönetimine terk etmek zorunda kalması ile doğuda Parthların, batıda Roma'nın yükselişi sonucu gerilemeye başlamıştır. Seleukoslar, yönetimi altındaki bölgelerde Pers ve Helenistik dönemlerde kullanılan satraplık sistemini kullanmaya devam etmişlerse de yerel yöneticilerin üzerinde yeterli baskıyı oluşturamamışlardır. Bu durum da merkezi yönetimin zayıfladığı durumlarda yerel yöneticilerin bağımsızlıklarını ilan etmesi ile sonuçlanmıştır. Anadolu'daki Helenistik krallıkların biranda ortaya çıkışına neden olan bu durum, Adiabene gibi krallıkların oluşumunun da temel nedeni olarak görülmektedir. Özellikle IV. Antiokhos Epiphanes döneminde, merkezi yönetimin ilgisi, Mısır ve Doğu Akdeniz üzerine odaklandığından, Adiabene'nin de içerisinde bulunduğu birçok krallığın daha bağımsız davrandığı görülmektedir. Bu açıdan bakıldığında Adiabene'nin Seleukos sonrası 
ortaya çıkan yerel krallıklardan biri olduğu kabul edilmektedir (Marciak, 2017, ss. 344 - 349; McKenzie, 1994, ss. 61 - 68).

\title{
Antik Kaynaklarda Adiabene Tarihi
}

Adiabene Krallı̆̆ı'nın kuruluşu ile ilgili bilgilerimiz her ne kadar sınırlı olsa dahi antik kaynaklardan ve yazıtlardan Adiabene'nin kralları ve tarihi önemi ile alakalı kısıtlı bilgiler elde edilebilmektedir. $\mathrm{Bu}$ bilgilerin büyük çoğunluğunu dönemin iki büyük devleti olan Roma ile Part krallıkları arasındaki mücadelede ve Roma'nın Anadolu'daki bağımsız krallıkları kontrolüne alma sürecinde oluşan savaş ortamında Adiabene ile ilgili bahislerden gelmektedir.

\begin{abstract}
"Lucullus başarl ile sürdürdüğü askeri seferinde Tigranocerta kentine ilerleyip burada kamp kurdu ve şehri kuşatmaya başladı. Buradaki pek çok şehirde olduğu gibi bu şehirde de (Tigranocerta) Kilikya'dan (zorla) nakledilmiş olan birçok Yunanlı ve Yunanlılarla aynı kaderi paylaşan Barbarlar vardı, (ayrıca) Tigranes tarafindan yerel şehirleri yıkılmış olan Adiabeneliler, Asurlar, Gordyeniler ve Kapadokyalılar da zorla ikamet ettirilmek için şehre (Tigranocerta) getirilmişlerdi. Şehir, adak sunumlart ile dolu olup büyük zenginliğe sahipti” (Plutarch, Lucullus 26.1-2)
\end{abstract}

Plutarkhos'un Lucullus'un yaşamını anlattığı eserinden alınan bölümde Tigranokerta kenti ve halkı ile ilgili bilgiler verilmektedir. Anlatıda öncelikle Büyük (II.) Tigranes'in yapmış olduğu askeri seferler sonucunda ele geçirmiş olduğu bölgelerdeki halkları zorunlu iskana tabi tutuğu ve özellikle ekonomik olarak güçlü kişilerin Tigranokerta şehrine yerleştirdiği açıklanmaktadır. Plutarkhos, bölgelere dayalı etnik unsurlardan bahsettiği gibi Asurlular gibi siyasi bir hakimiyeti olmayan toplumların varlığından da söz etmektedir. Tarih boyunca ele geçirilen bölgelerdeki isyanları önlemek ve siyasi hakimiyeti kabul ettirmek için zorunlu nüfus nakilleri uygulanmıştır. Bu uygulamayı en sistemli şekilde uygulayan ise Asurlar olmuştur. Bölgede binyıllardan beri geleneksel olarak uygulanan, zorunlu nüfus nakillerinden birini de Büyük (II.) Tigranes, gerçekleştirmiştir. Bu durumda Adiabene'nin de içerisinde bulunduğu birçok krallığın karmaşık bir nüfus yapısına sahip olmasına yol açmıştır.

\begin{abstract}
"Gerçekten de Mithradates VI Eupator hem gönderdiği haberciler hem de mektuplarla krall (Büyük (II.) Tigranes) savaşa katılmamaya ancak düşmanın (Lucullus) iaşe hatlarını kesmesini istedi, Mithradates VI Eupator'un Büyük (II.) Tigranes'e yardım etmesi için gönderdiği (Mithradates VI Eupator'un generali) Taxiles dahi savunmada kalınması ve Roma ordusunun güçlü silahlarının önüne çıkılmaması için yalvardı, Büyük (II.) Tigranes, bu tavsiyeleri ilk başta dinledi. Fakat tüm Armenia ve Gordyeni halkl ellerindeki tüm güçler ile Büyük (II.) Tigranes'in ordusuna katılınca ve Med ve Adiabene krallart ordularl ile birlikte gelince, Babil Denizinden (Basra Körfezi) birçok Arap (askerleri ile) destek verince (...) Büyük (II.) Tigranes zaferi paylaşmak için Mithradates VI Eupator'un bile beklemeyecekti.” (Plutarch, Lucullus 26.3-59)
\end{abstract}

Plutarkhos'un Lucullus'un Armenia Kralı Büyük (II.) Tigranes üzerine gerçekleştirmiş olduğu seferi anlattığı bölümde Adiabene kralının elindeki tüm güç ile Armenia Kralı Büyük (II.) Tigranes’e yardıma gelmiş olduğu belirtilmektedir. Roma'nın Anadolu'nun doğusunu hakimiyeti altına almak için uğraş verdiği bu dönemde, metinde de görüldüğü üzere hemen hemen tüm yerel krallıklar Roma hegemonyası altına girmemek için Büyük (II.) Tigranes’in öncülüğünde birleşme çabasına girmiş olduğu görülmektedir. Çünkü Roma, kendisi ile barış yapan krallıkları bile bir süre sonra yönetimi altına aldığından; Adiabene'nin de dahil olduğu bağımsız yerel krallıklar, gelecek Roma tehlikesini önlemek amacıyla bir arada hareket etmek istemiş olmalıdır. Fakat Plutarkhos, Adiabene kralının kim olduğundan ve sahip olduğu güçten bahsetmemektedir.

\footnotetext{
"Savaştan sonra Pompey, Hazar Denizine kadar yürümek için yola çıktı fakat sadece üç günlük mesafede iken çok sayıda ölümcül sürüngenden dolayı geri dönmek zorunda kaldı ve Küçük Armenia bölgesine çekildi. Burada Elyaean (Elam) ve Medlerin gönderdiği elçiler geldi ve onlara dostça cevap verildi. Fakat Gordyene bölgesine girerek Büyük (II.) Tigranes'den kalanları yağmalayan Part kralına karşı Afranius'un komutasında bir ordu gönderdi. Afranius
} 
komutasındaki ordu ile onları (Partları) Erbil'e kadar takip etti ve geri çekilmelerini sağladı." (Plutarch Pompey 36.1-2)

Plutarkhos’un Pompeius’un Armenia Kralı Büyük (II.) Tigranes’e karşı kazandığı zaferden sonrası anlatan metinde, Roma’nın Armenia krallığını kontrolü altına alması anlatılmaktadır. Metnin devamında Roma generali Afranius'un komutasındaki bir ordunun Erbil'e kadar ilerlediği belirtilmektedir. Bu durum da bize Roma'nın siyasi nüfuzunun bu dönemde Adiabene bölgesine kadar ulaşmış olduğunu göstermektedir. Fakat ilerleyen dönemde bölgenin hakim gücü olan Armenia Krallı̆̆ı'nın zayıflaması ve Roma'nın etkisinin Firat Nehri'nin batısıyla sınırlı kalması ile Adiabene daha bağımsız hareket etmeye başlamıştır. Adiabene'nin daha bağımsız hareket etmesinin ötesinde dönemin büyük krallıkları da bu bağımsızlığı tanımaya başlamıştır. Hatta Roma İmparatoru Augustus'un, günümüz Ankara ilinde yer alan kitabesinde Adiabene'nin kralı olan Artaxares'in ismi Roma ile müttefik olan krallar arasında yer almaktadır.

\begin{abstract}
“Kaçıp bana sı̆̆ınan krallar arasında Part kralı Tridates ve sonradan Phraates'in oğlu Phraates; Medlerin krall Artavasdes; Adiabene kralı Artaxares (...) vardl. Bundan başka, Partların krall ve Orodes'in oğlu Phraates, bütün oğullarını ve torunlarını bana, Italya'ya gönderdi. Bunu savaşta yenildiğinden dolayı değil, çocuklarının yaşamını ortaya koyarak dostluğumuzu kazanmak için yaptı. Başkanlı̆̆ım zamanında, o döneme dek aramızda hiçbir diplomatik ilişki ya da dostluk olmayan birçok başka ulus, Roma halkının bă̆lılı̆̆ını kazanmayı denediler." (Res Gestae Divi Augusti 32)
\end{abstract}

Roma İmparatoru Augustus'un vasiyeti de sayılan metin, bir yönetici olarak başarılarının da halkına ilanını içermektedir. Augustus, Artaxares'in de isminin geçmiş olduğu metinde Adiabene kralının kendisine olan bağlılığı belirtilmektedir. Adiabene Kralı Artaxares'in, Part ve Med kralları ile birlikte anılmış olması, bölgesinin güçlü krallarından biri olduğuna dair bir izlenim vermektedir. Fakat Adiabene Kralı Artaxares’in ismine ve yaptığı icraatlar ilişkin kaynaklar başka bir bilgi vermemektedir. Augustus dönemi ile Roma sahip olduğu topraklarda siyasi hakimiyetini pekiştirmeye çalışırken Part Krallığında taht mücadeleleri devam etmekteydi. Bu siyasi durum Adiabene kralları olan I. Izates ve Monobazos tarafından firsata çevrilmiş olmalıdır.

\begin{abstract}
"Bu sıralarda Adiabene kraliçesi Helena idi ve oğlu Izates ile birlikte yaşamlarının akışlarını değiștirerek Yahudi dinini ve geleneklerini benimsediler ve bu şöyle oldu: Adiabene krall olan Monobazus ki bu aynı zamanda Bazeus adını kullanıyordu, kız kardeşi Helena'ya aşık oldu ve onu karısı yapınca ondan çocuğu oldu. Ama bir gece onunla yatakta yatarken elini karısının karnına koydu ve uyuya kalınca elini karısının karnından çekmesi ve bebeğe zarar vermemesini isteyen bir ses duydu. (...) Hemen uyandı ve hikayeyi karısına anlattı. Oğlu doğunca da ona Izates adın verdi. (...) Monobazus bütün sevgisini biricik oğlu Izates'e vererek onu yetiştirdi. Fakat Monobazus'un diğer eşlerinden olan oğulları Izates'ten nefret ediyorlardı. (...) Monobazus oğlu Izates'i birçok hediye ile (günümüz Susa kent çevresinde olan) Charax-Spasini kralı Abennerig'e gönderdi. Çünkü kardeşlerinin ona duyduğu nefretten dolayı sıkıntıya girmesini istemiyordu. Kral Abennerig, genç adamı memnuniyet ile karşıladı, ona büyük bir sevgi besledi ve Izates'i kızı Samacha ile evlendirdi. Ancak Monobazus yaşlandığında ve yaşayacak az zamanı kaldığını anlayınca ölmeden önce oğlunu görmek istedi. Gönderdiği elçiler ile gelen Izates’i kucakladı ve ona Carrae denen yeri yönetmesi için verdi. Burada Nuh'un tufandan kaçmış olduğu geminin kalıntılarının olduğu yer olup görmek isteyenler hala onu orada görebilir. (...) (Sonra) Izates babasının öldüğ̈̈nü duyunca hızla çıkıp geldi ve kardeşi olan Monobazus krallığı Izates'e bıraktı. Izates, Charax Spasini'de kaldı̆̆ zamanlarda Ananias isimli bir Yahudi tüccar, krala ait olan kadınların arasına girerek onlara Yahudi dinine göre tapınmayı ögretmişti. Ayrıca Izates ile de tanışmış ve onun da Yahudi dinini benimsemesini sağlamıştır. Hatta bu Yahudi tüccar, babas tarafindan Adiabene'ye gelmesi için çă̆ırıldiğında ona eşlik etmişti." (Josephus, Antiquities of the Jews 20.2 1-5)
\end{abstract}

Adiabene kraliçelerinin en ünlüsü olan Helena ve oğlu II. Izates’in Yahudi dinini seçmelerini efsanevi bir üslupla anlatan Josephus diğer antik yazarlardan daha farklı bir bakış açısı sunmuştur. Josephus, doğumu tanrısal bir nedene bağlı olan ve belki de bir noktada tanrısal seçilmişliği bulunan II. Izates'in, Tevrat anlatımlarına benzer bir biçimde önce ülkesinden uzaklara gitmesi, orada kaldığı 
sürede tanıştığı bir Yahudi tüccar vasıtası ile Josephus'a göre hakiki dini bulması ve dönüşte Nuh'un gemisinin kalıntılarının bulunduğu kutsal bir yere gidişi ile nihayetinde kral oluşunu anlatmaktadır. Josephus'un anlatımını tarihsel veriler ile kanıtlamamızın veya çürütmemiz çok mümkün gözükmese dahi, Adiabene krallarının bir dönem Yahudi dinini benimsemiş olduğu kabul edilebilir. Fakat halkın da kralları gibi Yahudi dinini benimsemiş olduğunu kabul etmek pek mümkün gözükmemektedir. Ayrıca Josephus'un anlatımında belirttiği üzere Yahudi dinini bir tüccar vasıtası ile kabul etmiş olmaları belki de krallığa ekonomik kazanç veya siyasi destek sağlama amacını taşımaktadır. Josephus'un anlatımının devamında Izates'in ülkeyi barış içinde yönetmesi üzerine Helena'nın Kudüs'e bir ziyaret gerçekleştiği ve bu esnada kıtlık ile mücadele eden halka yardım ettiği belirtilmektedir (Marciak, 2011b, ss. 63 - 83; Marciak, 2018, ss. 607 - 624; Marciakb, 2014; Neusner, 1964, ss. 60 - 66).

\begin{abstract}
“(Syria Eyaleti’nin yöneticisi olan) Gaius Cassius, bir hukukçu olarak rakipsiz olduğundan; savaş sanatları kaybolmuştu ve barış, tek düze bir miskinlik halinde devam etmekteydi. Eski savaş disiplini kanunlarının uygulanması oldukça uzaktaydı. Yine de onun lejyonları devamlı antrenman yaparak düşman yakındaymış gibi özenli ve dikkatli davranmaktaydl. Akıllıca davranarak nehri geçmek için en uygun rota olan Zeugma'da kampını kurdurdu. Sonra Parthların nüfuzlu adamlarlyla Arap prensi Acbarus oraya vardl. O, Meherdates'i barbarlarin heyecanina karşı dikkatli olmasl, soğuk havanin gittikçe artması ve ihanetlere karşı uyardl. (...) Sonunda kardan yıpranmış dăg yollarını aşıp ovaya yaklaştıklarında Carenes'in kuvvetleri onlara yaklaş̧ı ve birlikte Dicle Nehri'ni geçerek Kral Izates'in ülkesi olan Adiabene'ye hizla girdiler, Kral Izates'in Meherdates ile özel bir dostluğu daha ötesinde samimiyeti vardl. Ancak yol üzerinde Pers Kralı Darius'un İskender'e yenildiği son savaşın geçtiği ünlü kale ile bir zamanlar Asur'un onurlu kraliyet kenti olan Ninova'y ele geçirdiler. (...) (Ilerleyiş devam ederken) henüz ordusu yeteri kadar güçlenmemiş olan Gotarzes (Dicle’nin doğu kollarından biri olan) Corma nehrini doğal bir bariyer olarak kullanmış ve tüm alaycı mesajlara rağmen savaşa girişmemiştir. Önce Izates ve Adiabene birlikleri sonra Acbarus ve onun Arap (askerleri) yola çıkt." (Tacitus, Annals 12. 1214.)
\end{abstract}

Tacitus'dan alınmış olan metinde yaklaşık MS 50 yılında Part Kralı II. Gotarzes'e karşı ayaklanan Meherdates'in Roma ve müttefiklerinden almış olduğu yardım ile Fırat Nehri'ni Zeugma üzerinden geçmesi ve sonrasında yaşanan savaşta yenilmesi anlatılmaktadır. Metnin çalışmamız için değerli olan kısmı ise Adiabene'nin bu dönemde büyük siyasi mücadelelere katılabilecek kadar önemli bir krallık olması ile kral II. Izates'in dönemin siyasi konjonktüründeki yerini göstermesidir. Adiabene Krallığının, bu dönemde, Roma ve Part güçleri arasındaki mücadelelerde taraf olarak kadar belirgin bir güce sahip olduğunu görmekteyiz. Tacitus'un metni bize II. Gotarzes'e karşı ayaklanan Meherdates'in yanında yer alan Izates'in diğer siyasi faaliyetleri ile ilgili bilgi vermemektedir. Fakat metin, bu dönemde dahi tarihçilerin hafızasından Asur'un kraliyet kenti Ninova'nın ve Büyük İskender'in Darius'u yendiği Gaugamela'nın silinmediğini göstermesi açısından önemlidir.

\begin{abstract}
“Part Kralı (I.) Vologeses, Corbulo'nın başarlarindan ve Tigranes'in Armenia tahtına yükselmesinden övgü ile söz etti ve kardeşi Tiridates'in (Roma'dan) sınır dışı edilmesi ile Arşak soyunun görkemine yapılan saldırının intikamının alınmasından da endişeliydi, öte yandan Roma (Carrhae Savaş'ndan sonra) yapılmış olan uzun süreli antlaşmanın gücüne inanıyor ve (antlaşmaya) saygı duyuyordu. (...) Armenia tahtına çıkan (VI.) Tigranes, sinır komşusu olan Adiabene'ye bir yağma seferi gerçekleştirmiş ve (topraklarının büyük kısmını) harap etmişti. (...) Onların kizginlikları Adiabene'nin yöneticisi olan (II.) Monobazus tarafindan alevlendirildi. $O$ (Monobazus) nasll bir koruma istiyordu? Armenia zaten (Roma tarafindan) terk edilmişti, (şimdi o) komşusu olan bir ülkeyi tahrip ediyordu. Ĕger Partlar korumayı redederse Roma boyunduruğu teslim olmuş bir ulustan çok fethedilmiş bir ulusun üzerinde kalacaktt." (Tacitus, Annals 11. 1.)
\end{abstract}

MS 58 yılında Armenia Krallığı üzerine bir sefer düzenleyen Roma generali Corbulo, Tigranocerta'yı ele geçirdikten sonra ülke bir direniş göstermeden teslim oldu. Bu itaatin karşısında Roma imparatoru Nero, Armenia'yı yönetmesi için Kapadokya soyundan gelen Tigranes'i atadı. Tahta çıkan VI. Tigranes, Roma'dan izin almadan komşu krallık olan Adiabene'ye büyük bir yağma seferi düzenleyip Roma tarafindan kabul edilmiş olan II. Monobazes'i esir etti. Tacitus'dan alınmış olan metin, bu tarihsel olayı Roma gözünden anlatırken, Part Kralı I. Vologeses, bu yağmanın krallığına 
karş1 bir Roma komplosu olduğunu iddia etti. Sonrasında I. Vologeses, ordusu ile Armenia topraklarına girerek Tigranocerta'yı kuşattı. Bu esnada kendi iç sorunları ile uğraşan Roma, Partlar ile bir savaşa girmektense anlaşma yollarını aramaktaydı (Edwell, 2007, s. 23; Shotter, 2003, s. 38; Sykes, 2004, s. 378).

\begin{abstract}
"Her iki tarafta da uzun görüşmelerden sonra, Adiabene Kralı Monobazes, anlaşmanın sonuçlandırılmasına tanık olması için ertesi gün getirildi. Anlaşma, birliklerin kuşatmalarının kaldırlması, tüm (Part) askerlerinin Armenia topraklarından çekilmesi ile kalelerin ve malzemelerin Partlara teslim edilmesini içermekteydi. Bütün bunlar tamamlandığında, I. Vologeses'e Nero'ya bir elçilik heyeti gönderme izni verilecekti.” (Tacitus, Annals 11. 14.)
\end{abstract}

Tacitus'un metnin devamında Roma ile Partlar arasındaki görüşmeler anlatılmaktadır. Uzun süren görüşmelerin ardından Roma ve Partlar eski sınırlarına çekilirken Tiridates'in Armenia kralı olması üzerinde anlaşıldı. Fakat Tiridates, Roma şehrine gidecek ve tacı İmparator Nero'nun elinden alacaktı. Böylece Armenia Roma'ya bağlı bir krallık statüsüne sahip olmuştur. Bu esnada Adiabene Kralı II. Monobazes de krallığını geri almış olsa da önce Armenia tarafından yıkıma uğrayan sonrasında Partlar tarafından geçici de olsa işgal edilen ülke bir ekonomik ve siyasi olarak çöküntüye uğramıştı. Adiabene'nin Roma ve Part arasındaki mücadeledeki öneminin ortaya çıktı̆̆ı bu olay Cassius Dio tarafından da farklı birkaç ayrıntı ile anlatılmıştır.

\begin{abstract}
“Part Kralı (I.) Vologeses, Nero’nun Armenia tahtını bir başkasına verdiğini ve (yeni kral) Tigranes’in Adiabene ülkesini yağmaladığını duyunca Corbulo’ya karşı savaşmak için hazırlıklara başladı ve Adiabene Kralı Monobazes'i ve bir Partlı olan Monaeses'i (beraberlerinde bir ordu ile) Armenia üzerine gönderdi. Bu ikisi Tigranocerta'yı kuşattı ama bir sonuç alamadılar. Hatta bu ikisinin emrindeki yerli birlikler ve Part ordusunun bir kısmı Romalılar tarafindan geri püskürtüldüler ve Corbulo'ya karşı dikkatli olması gereken (I.) Vologeses, gururunu yuttu ve seferden vazgeçti. Daha sonra (I.) Vologeses, Corbulo'ya haber gönderip Nero'ya bir elçilik heyeti göndermesi karşılığında, kuşatmayı kaldırdı ve askerlerini Armenia topraklarından geri çekti.” (Cassius Dio, Roman History 62. 20. 1-3)
\end{abstract}

Cassius Dio'dan alınmış olan metin yine I. Vologeses ile İmparator Nero arasındaki mücadeleden bahsetmektedir. Fakat Tacitus, Adiabene Kralı II. Monobazus'un esir alınmış olduğunu söylerken Cassius Dio, onun Partlara sığınmış olduğunu iddia etmektedir. Temelde aynı fakat ayrıntıda farklılaşan bu iki anlatımdan hangisinin doğru olduğunu söylememiz oldukça zordur. Yine de Adiabene Krallığı ile Partlar arasında coğrafi yakınlığa dayanan bir müttefiklik olduğu göz önüne alınırsa Cassius Dio'nun anlatımının daha güçlü olduğu söylenebilir. Ayrıca ilerleyen dönemde özellikle Roma'nın desteklediği Armenia Krallığı'nın Adiabene üzerindeki hak iddialarının Partlar ile müttefikliği zorunlu kıldığını görmekteyiz.

\begin{abstract}
"Baharın başlangıcında Traianus, düşman ülkesine doğru hızla ilerledi. Dicle Nehri’nin kıyısındaki bölgede gemi yapımı için uygun keresteler olmadı̆̆ından dolayı Nisibis (Nusaybin) civarındaki ormanlardan elde ettiği kereste ile yaptırdı $\breve{g}_{l}$ gemileri atl arabalar ile nehre getirtti, (bu gemiler) parçalara ayrılıp yeniden bir araya getirilecek şekilde inşa edilmişti. Barbarlar karşı kıyıda bekleyip onun ilerleyişini engellemeye çalıştıkları için Gordyaean Dağları 'nın karşısındaki nehri geçmekte büyük zorluklar yaşadl. Fakat Traianus hem büyük miktarda askere hem de gemiye sahipti. (...) Sonuçta Romalılar nehrin karşısına geçip Adiabene'nin tamamına sahip olmayı başardılar. Bu bölge, Asur'un toprakları olup Ninova şehri de buradadır, (ayrıca) İskender'in Darius'u yenmiş olduğu Gaugamela ve Erbil de bu bölgede bulunur. Adiabene barbarların dilinde Atyria olarak adlandırılmıştı, (şimdi) T (harfi) çift $S$ (harfi) ile değiştirildi.” (Cassius Dio, Roman History 6. 26. 1-4)
\end{abstract}

Cassius Dio'dan alınmış olan metin Traianus'un doğu seferi esnasında Adiabene'nin Roma yönetimi altına nasıl girdiğini anlatmaktadır. Traianus, doğu sınırlarını genişletmek için MS 113 yılında Part Krallığı üzerine çok büyük bir ordu ile sefer çıkmıştır. Traianus, Roma ve Partlar arasındaki geleneksel sınır olan Fırat Nehrini geçmiş ve Armenia topraklarını doğrudan Roma'ya bağlamıştır. Böylece uzun zamandan beri devam eden Armenia sorunu çözülmüş bölge, Roma'nın bir eyaleti haline getirilmiştir. Sonrasında Partlar ile ittifak kuracağından şüphelenilen Edessa Kralı VII. 
Abgarus itaat altına alınmış ve Nisibis ile Batnae şehirleri, Roma'ya bağlanmıştır. Anadolu'nun güneydoğusunu ele geçiren Traianus, Dicle Nehrini geçmiş ve Adiabene Krallı̆̆ını, Roma yönetimi altına almıştır. Adiabene Krallığının toprakları, Roma'nın Assyria eyaletine dönüştürülmüştür. Adiabene kralı Meharaspes ise kaçmak zorunda kalmıştır. Böylece Adiabene Krallı̆̆ı'nın sahip olduğu topraklar doğrudan Roma'ya bağlanmıştır (Bennett, 1997, ss. 15 - 44; Farrokh, 2007, ss. 158 - 161; Henderson, 1969, ss. 327; Lepper, 1948, ss. 48 - 49).

\section{Sonuç}

Adiabene Krallığı, bağımsız bir biçimde yönetildiği yaklaşık bir yüzyıl boyunca, Romalılar ve Partlar arasında devam eden mücadeleden dolayı, bu iki büyük askeri ve siyasi gücün gölgesinde kalmıştır. Fakat Adiabene Krallığı'nın kurulduğu bölge olan Kuzey Mezopotamya, binyılların kültürel birikimine sahip bir coğrafyadır. Bölge yaklaşık bin beş yüz yıl süren Asur hakimiyeti döneminde Ön Asya'nın siyasi ve kültürel merkezi olmuştur. Fakat Medlerin, Asur'un kraliyet kenti Ninova'yı ele geçirmesinden sonra Adiabene bölgesi, Med ve Perslerin yönetimindeki Babil Satraplı̆̆ının bir bölgesi olmaktan ileri gidememiştir. Bu durum da Asur dönemindeki gelişmişliğe kıyasla, bölgenin önemini oldukça azaltmıştır. Bu dönemden sonraki tarihsel kayıtlar, Adiabene bölgesi ile ilgili en fazla Büyük İskender'in Darius'u yenmiş olduğu Gaugamela'dan bahsetmenin ötesine geçmemiştir. Pers hakimiyetinin son bulmasının ardından başlayan dönemde ise Adiabene, Seleukoslara bağlı bir konumuna gerilemiştir. Seleukos hakimiyetinin zayıflaması ile de bağımsız bir krallık olarak ortaya çıkmıştır.

Bağımsız bir krallık olan Adiabene'nin siyasi sınırları genellikle komşu krallıklara kıyasla belirlenmişken birçok antik yazar Adiabene olarak isimlendirilen bölgenin coğrafi sınırları hakkında bilgi vermiştir. Strabon, Ammianus Marcellinus ve Yaşlı Plinius'in anlatımlarına göre Adiabene, batıda Dicle Nehri, güneyde Küçük Zap Nehri, doğuda Zağros Dağları ile sınırlandırılmış, kuzey sınırı için antik yazarlar Gordyaean Dağlarını referans alınmıştır. Bölge, Asur Krallığı döneminden itibaren geleneksel bir politika haline gelen zorunlu nüfus nakillerinden dolayı homojen bir nüfusa sahip değildi. Ayrıca Pers ve Med dönemlerinde günümüz İran coğrafyasından getirilen halkların başta Ninova şehri olmak üzere bölgeye yerleştirildiği, Roma döneminde Kilikia'dan Yunanlıların ve diğer bölgelerden başka etnik unsurların zorunlu biçimde iskan edilmiş olduğu antik yazarlar tarafindan belirtilmektedir.

Adiabene Krallığı için bir diğer bilinmezlik ise nasıl kurulmuş olduğudur. Mevcut kanıtlar Adiabene'nin Seloukos sonrası ortaya çıkan yerel krallıklardan biri olduğunu göstermiş olsa dahi, antik yazarların anlatımlarında bu durumun ayrıntılarına rastlanamamaktadır. Adiabene Krallığı ile ilgili en erken bilgileri Plutarkhos'un Lucullus'un yaşamını anlattığı eserinden öğrenmekteyiz. Plutarkhos, Büyük (II.) Tigranes'in bölgeye yaptığı zorunlu nüfus nakillerinden ve Roma'nın askeri gücünü bölgeye yerleştirmesinden bahsetmektedir. Yine Plutarkhos, Pompeius'un hayatını anlattığı eserde ise Roma'nın gücünün günümüzdeki Erbil'e kadar ulaştığını anlatmaktadır. Bu anlatımda Adiabene Krallığı'nın Roma ile siyasi ve askeri ilişki içerisinde olduğunu göstermektedir. Bu durumun bir diğer ispatı ise Roma İmparatoru Augustus'un vasiyeti olup bu vasiyette Adiabene Kralı Artaxares'in Roma'ya sadık olduğundan bahsedilmesidir. Yine bu metinde bilinen en eski Adiabene kralı olan Artaxares'in ismi geçmektedir.

Antik yazarlardan olan Josephus, Adiabene Krallığı'nın yöneticileri hakkındaki en geniş bilgiyi vermesine rağmen siyasi olayları anlatmaktan çok Helena ve oğlu II. Izates'in Yahudi dinini seçmeleri üzerinde durmaktadır. Adiabene Krallı̆̆ı'nın siyasi durumu ile ilgili önemli bilgilerden bir kısmı Tacitus tarafından verilmektedir. Tacitus, Part Kralı II. Gotarzes'e karşı ayaklanan Meherdates'e yardım edenler arasında Adiabene Kralı II. Izates'in de bulunduğunu belirtmektedir. Bu anlatı, Adiabene'nin bulunduğu bölgedeki siyasi çekişmelerin içinde yer alabilecek güçte olduğunu göstermektedir. Ayrıca Tacitus, Roma İmparatoru Nero döneminde Partlar ile ortaya çıkan Armenia sorununun çözümünde Adiabene Kralı II. Monobazes’in de yer aldığını açıklamaktadır. 
Adiabene Krallığı yaklaşık yüz yıl Roma ve Partlar arasında izlemiş olduğu denge politikası ile varlığını sürdürmüş olsa da Roma İmparatoru Traianus'un doğu seferinin karşısında duramamıştır. Cassius Dio'ya göre Traianus, Dicle Nehrini geçmiş ve Adiabene Krallığını, Roma yönetimi altına almıştır. Yerel halkın Atyria olarak isimlendirdiği bölgenin ismini Assyria şeklinde değiştirmiştir. Böylece Adiabene Krallığının toprakları, Roma’nın Assyria eyaletine dönüştürülmüştür.

\section{Yazarların Katkı Oranı}

Çalışma tek yazarlı olduğu için yazarın katkı oranı \%100'dür.

\section{Çıkar Çatışması}

Bu çalışmada çıkar çatışması oluşturacak bir husus yoktur.

\section{Kaynaklar}

Ataç, M. A. (2010). The mythology of kingship in Neo-Assyrian Art. Cambridge: Cambridge University Press.

Bennett, J. (1997). Trajan. London: Routledge Press.

Caesar, A. (2009). Ankara anıtı. (Çiğdem Dürüşken Çev.). İstanbul: Kabalc1 Yayınevi.

Cline, E. H. and Graham, M. W. (2011). Ancient empires: From Mesopotamia to the rise of Islam. Cambridge: Cambridge University Press.

Dalley, S. (1993). Nineveh after 612 BC. Altorientalische Forschungen, 20 (1), 134-147.

Dio, C. (1954) Historia Romana (E. Carry, Çev.). London: Loeb.

Edwell, P. (2007). Between Rome and Persia, the middle Euphrates, Mesopotamia and Palmyra under Roman control. New York: Routledge Press.

Farrokh, K. (2007). Shadows in the desert: Ancient Persia at war. New York: Osprey Publishing.

Gökçek, L. G. (2015). Asurlular. Ankara: Bilgin Kültür Sanat Yayınları.

Henderson, B.W. (1969). Five Roman emperors: Vespasian, Titus, Domitian, Nerva, Traianus, A.D. 69-117. Cambridge: Cambridge University Press.

Holloway, S. W. (2002). Assur is king. Assur is king! Religion in the exercise of power in the NeoAssyrian empire. Leiden: Brill.

Johnston, C. (1901). The fall of Nineveh. Journal of the American Oriental Society, 22, 20-22.

Josephus, F. (1961). Bellum Iudaecum. (H. J. Thackeray, Çev.). London: Loeb.

Josephus. (1965). Jewish Antiquities. (L. H. Feldman, Çev.). London: Loeb.

Karlsson, M. (2016). Relations of power in early Neo-Assyrian state ideology. Berlin: Walter de Gruyter.

Kuhrt, A. (2010). The Persian empire: A corpus of sources from the Achaemenid Period. London: Routledge.

Larsen, M.T. (1977). Partnership in the Old Assyrian trade. Iraq, 39, 119-145. 
Lepper, F.A. (1948). Trajan's parthian war. Oxford: Oxford University Press.

Liverani, M. (2017). Thoughts on the Assyrian empire and Assyrian kingship. 534-545, (Ed. Eckart Frahm) A Companion to Assyria. Oxford: Blackwell.

MacGinnis, J. D. (1988). Ctesias and the fall of Nineveh. Illinois Classical Studies, 13(1), 37-42.

Marcellinus, A. (1963). Rerum Gestarum Libri (J. C. Rolfe, Çev.), London: Loeb.

Marciak, M. (2011a). Seleucid-Parthian Adiabene in the light of ancient geographical and ethnographical texts. Anabasis, 2, 179-208.

Marciak, M. (2011b). Biblical allusions in the Adiabene narrative (Antiquitates Judaicae 20: 17-96). The Polish Journal of Biblical Research, 10, 63-83.

Marciak, M. (2014a). The cultural environment of Adiabene in the Hellenistic, Parthian, and Sasanian periods. Parthica. Incontri di culture nel mondo antico, 16, 111-150.

Marciak, M. (2014b). Izates, Helena, and Monobazos of Adiabene. A study on literary traditions and history. Wiesbaden: Harrassowitz Verlag.

Marciak, M. (2017). Sophene, Gordyene, and Adiabene: Three regna minora of northern Mesopotamia between East and West. Leiden: Brill.

Marciak, M. (2018). Royal converts from Adiabene and Jewish identity in the Second Temple Period. The Biblical Annals, 8(4), 607-624.

Mavrojannis, T. (2017). Alexander the Great "King of Asia" at Arbela and Babylon in October 331 BC his ecumenical Macedonian-- Persian ideology. Geographia Antiqua, 26, 121-150.

McKenzie, L. (1994). Patterns in Seleucid administration: Macedonian or Near Eastern?. Mediterranean Archaeology, 7, 61-68.

Neusner, J. (1964). The Conversion of Adiabene to Judaism: A new perspective. Journal of Biblical Literature, 83, 60-66.

Parpola, Simo (2004). Assyrian identity in ancient times and today. Journal of Assyrian Academic Studies, 18, 5-49.

Plutarkhos. (1914). Bioi Paralleloi (Lucullus). (B. Perin, Çev.). London: Loeb.

Reade, J. (1998). Greco-Parthian Nineveh. Iraq, 60, 65-83.

Reade, J. (2001). More about Adiabene. Iraq, 63, 187-199.

Shotter, D. (1997). Nero. New York: Routledge Press.

Strabon. (1957). Geographika, (H. L. Jones, Çev.). London: Loeb.

Sykes, P. M. (2004). History of Persia. London: Routledge Press.

Tacitus, C. (1962). Historiae. (C. H. Moore and J. Jackson Çev.). London: Loeb.

Yamada, S. (2000). The construction of the Assyrian Empire. Leiden: Brill.

Zawadzki, S., Wolko, U. and Lavelle, P. (1988). The fall of Assyria and Median-Babylonian relations in light of the Nabopolassar chronicle. Poznań: Adam Mickiewicz University Press. 


\section{Extended Abstract}

\section{Introduction}

The region named Adiabene in ancient sources constitutes the central geography of the Assyrian kingdom. The region remained under Assyrian rule for most of the period from $2000 \mathrm{BC}$ to 612 BC. Although the majority of the population was Assyrians during this period, it is known that the Hurri community has an important place in the ethnic structure of the region. They ruled the lands that would be owned by the Kingdom of Adiabene around 1450 - $1350 \mathrm{BC}$, when the Hurri community reached the state of nationalization with the Mitanni people. During the New Assyrian Kingdom, which constitutes the last four hundred years of Assyrian history, great military, political and economic developments took place. Powerful Assyrian kings, became taxable from the entire Asia Minor world with their military expeditions which took place one after another. The Assyrian kings, enriched with these taxes, built many magnificent cities in the region where Adiabene will be located. The most famous among these was the city of Nineveh. As can be seen in the cuneiform text describing the capture of the city of Nineveh by the Medes and its collapse, the centuries-old Assyrian civilization and wealth disappeared with the destruction of the most magnificent and central city of the Adiabene region. The region came under the rule of the Medes and could not gain the qualification of being a political center again. After the Persians conquered the entire Mesopotamia, the region was attached to the Babylonian Satrap and crushed under heavy taxes. Macedonian domination began in the Adiabene region after nearly three hundred years of Persian domination. Alexander the Great, who went on the eastern expedition and captured the majority of Persian lands, he made his last war with the Persians in Gaugamela within the borders of Adiabene region on his way back from Egypt. Considering that Gaugamela is located just east of Mosul today, it is seen that Adiabene region passed under Macedonian rule from Persia in 322 BC. The Adiabene region, which was under the rule of the Seleucid Kingdom after Alexander the Great, became an independent kingdom with the weakening of the Seleucid rule.

\section{Geographical Boundaries of Adiabene}

Although it is known that the lands owned by the Kingdom of Adiabene are the central geography of the Assyrian Kingdom, ancient authors put forward different and similar views while giving information about the borders of the region. It is known that the basis of this situation is the periodic differences in political boundaries, different geographical elements used by ancient writers, and the beginning of the recognition of certain parts of the region with new names. While many ancient writers restricted Adiabene with rivers, some authors gave the names of other neighboring kingdoms. Nevertheless, the ancient authors, who stated the boundaries of Adiabene, also counted the important cities of the region and limited them based on the city location. When the accounts of ancient authors are taken as reference, it can be accepted that the western border of the Kingdom of Adiabene is the Tigris River and the southern border is the Little Zap River. The northern border can be extended to the north of Lake Van based on the claim that it is the Gordyaean Mountains. Although the eastern border of Adiabene changes depending on its political power, it is estimated that it ends on the western slopes of the Zagros Mountains.

\section{The Establishment of the Kingdom of Adiabene}

The first emergence of the region called Adiabene with an independent management cannot go beyond estimates and comparisons due to the insufficient data available. After the collapse of Assyria with the rise of the Persians in Asia Minor, the power center of Asia Minor shifted to today's Iranian geography and the written sources on Northern Mesopotamia, including Adiabene, have decreased. The central governments of the Hellenistic Kingdoms established after Alexander the Great's destruction of the Persian Kingdom were also geographically far from the Adiabene region. This situation caused Abiabene not to take much place in the historical records. Until Alexander the Great's eastern expedition and the collapse of the Persians, the Adiabene region, which was probably a region of Babylonian satrapy, remained under the rule of Seleucus, a Hellenistic kingdom, after 305 BC. 
However, when Seleucus Nicator the first moved her capital to Antakya in 300 BC, Adiabene lost its strategic position with its proximity to the old royal city Babylon. This situation, which caused the emergence of Hellenistic kingdoms in Anatolia, is seen as the main reason for the formation of kingdoms such as Adiabene. Especially in the period of Antiochus Epifanis IV, it is seen that many kingdoms, including Adiabene, acted more independently, as the central government's interest focused on Egypt and the Eastern Mediterranean. From this point of view, it can be accepted that Adiabene is one of the local kingdoms that emerged after Seloukos.

\section{Adiabene History in Ancient Sources}

Although our knowledge about the establishment of the Adiabene kingdom is limited, limited information can be obtained from ancient sources and inscriptions about the kings of Adiabene and their historical significance. Most of this information about Adiabene comes from the tellings during the war between the two great states of the period, Rome and the Parthian kingdoms, and the wars that occurred during the process of Rome taking control of the independent kingdoms in Anatolia. In the section that describes the life of Lucullus in Plutarch's work, information is given about the city of Tigranokerta and its people. In the narrative, it is explained that the peoples of the regions captured by the Great (II.) Tigranes as a result of the military expeditions were forced to settlement and especially economically strong people settled in the city of Tigranokerta. As Plutarch mentions ethnic elements based on regions, she also mentions the existence of societies that do not have a political domination such as Assyrians. Rome's control of the kingdom of Armenia is described, in the text of Plutarch's, which tells about Pompey 's victory over Tigranes the Great (II.), King of Armenia. In the rest of the text, it is stated that an army under the command of the Roman General Afranius advanced up to Erbil. Josephus who described, the most famous of the Adiabene queens, Helena and her son II. Izates' choice of the Jewish religion in a legendary style, offered a different perspective than other ancient writers. In the text taken from Tacitus, it is explained that Meherdates, who rebelled against Gotarzes the second in about $50 \mathrm{AD}$, crossed the Euphrates River over Zeugma with the help of Rome and its allies and was defeated in the war that followed. The text taken from CassiusDio also mentions the struggle between Vologeses the First and Emperor Nero. But while Tacitus says King of Adiabene, Monobazus the second, was taken prisoner, CassiusDio claims that he took refuge in the Parthians. The text taken from CassiusDio describes how Adiabene came under Roman rule during Trajan's eastern expedition. Trajan embarked on a campaign with a very large army over the Parthian Kingdom in $113 \mathrm{AD}$ to expand its eastern borders. Trajan crossed the Euphrates River, the traditional border between Rome and the Parthians, and connected Armenia directly to Rome. Thus, Armenia problem, which has been going on for a long time, has been solved and the region has been turned into a province of Rome. Afterwards King of Edessa, Abgarus the seventh, who was suspected of allying with the Parthians, was subordinated and the cities of Nisibis and Batnae were attached to Rome. Capturing the southeast of Anatolia, Trajan crossed the Tigris River and took the Adiabene Kingdom under Roman rule. The lands of the Kingdom of Adiabene were transformed into the Roman province of Assyria. The King of Adiabene, Meharaspes, had to flee. Thus, the lands owned by the Kingdom of Adiabene were directly connected to Rome. 